\title{
Comparison of Visual Analog Pain Score Reported to Physician vs Nurse in Nonoperatively Treated Foot and Ankle Patients
}

Trevor McBride, BS

Thomas Jefferson University

MAJ Kevin D. Martin, DO

Evans Army Hospital

CPT Jeffrey Wake, DO, ATC

Madigan Army Medical Center

LT J. Preston Van Buren, DO

Evans Army Hospital

Cuyler Dewar, BS

The University Of Michigan

Follow this and additional works at: https://jdc.jefferson.edu/si_ctr_2021_phase1

Part of the Orthopedics Commons

Let us know how access to this document benefits you

\section{Recommended Citation}

McBride, Trevor; Martin, Kevin D.; Wake, Jeffrey; Van Buren, Preston; Dewar, Cuyler, "Comparison of Visual Analog Pain Score Reported to Physician vs Nurse in Nonoperatively Treated Foot and Ankle Patients" (2019). SKMC JeffMD Scholarly Inquiry, Phase 1, Project 1.

This Article is brought to you for free and open access by the Jefferson Digital Commons. The Jefferson Digital Commons is a service of Thomas Jefferson University's Center for Teaching and Learning (CTL). The Commons is a showcase for Jefferson books and journals, peer-reviewed scholarly publications, unique historical collections from the University archives, and teaching tools. The Jefferson Digital Commons allows researchers and interested readers anywhere in the world to learn about and keep up to date with Jefferson scholarship. This article has been accepted for inclusion in Phase 1 by an authorized administrator of the Jefferson Digital Commons. For more information, please contact: JeffersonDigitalCommons@jefferson.edu. 
Trevor McBride

SKMC Class of 2021

SI CTR Abstract

Date: $12 / 15 / 18$

\section{Comparison of Visual Analog Pain Score Reported to Physician vs Nurse in Nonoperatively Treated Foot and Ankle Patients}

Background: Patient reported outcome measures (PROMs) are taking a more prominent role in Orthopedics as health care seeks to define treatment outcomes. The Visual Analogue Scale (VAS) is considered a reliable measure of acute pain. A previous study found that operative candidates' VAS pain score was significantly higher when reported to the surgeon compared to the nurse. This study's aim is to examine whether this phenomenon occurs in nonoperative patients. We hypothesize that patients' VAS scores reported to the surgeon and a nurse will be the same

Methods: This study is a retrospective cohort of 201 consecutive nonoperative patients treated by a single surgeon. Patients were asked to rate pain intensity by a nurse followed by the surgeon using a horizontal VAS, 0 "no pain" to 10 "worst pain". Differences in reported pain levels were compared with data from the previous cohort of 201 consecutive operative patients.

Results: The mean VAS score reported to the nurse was 3.2 whereas the mean VAS score reported to the surgeon was $4.2(p<.001)$. The mean difference in VAS scores reported for operative patients was 2.9 , whereas the mean difference for nonoperative patients was $1.0(p<.001)$.

Conclusion: This study found statistically significant differences between VAS scores reported to the surgeon versus the nurse in nonoperative patients which support the trend found in our previous study, where operative patients reported significantly higher scores to the surgeon. The mean difference between reported pain scores is significantly higher for operative patients compared to nonoperative patients. 